Vitor Hugo Schell

\title{
Die Areopagrede des Paulus und Reden bei Josephus
}

Eine vergleichende Studie zu Apg 17 und dem historiographischen Werk des Josephus

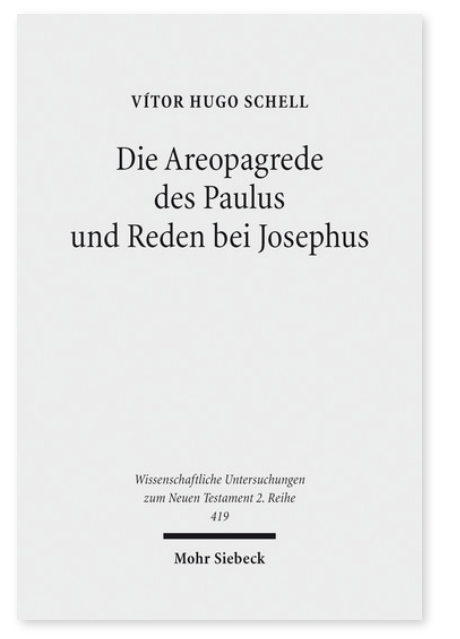

2016. XII, 317 Seiten. WUNT II 419

ISBN 978-3-16-154227-5

DOI 10.1628/978-3-16-154227-5

eBook PDF 104,00€

ISBN 978-3-16-154226-8

fadengeheftete Broschur 104,00€
Vítor Hugo Schell betrachtet die Apostelgeschichte als historisches Kunstwerk und versucht, durch die Analyse der Areopagrede im 17. Kapitel, neue Facetten der literarischen Strategien ihres Verfassers zu entdecken. Durch einen Vergleich mit Josephus gewinnt er eine neue Perspektive der wissenschaftlichen Betrachtung der Apg und der Areopagrede. Die Areopagrede wird den Reden aus Bellum und Antiquitates, den zwei längsten Darstellungen des Josephus und den einzigen erhaltenen Beispielen einer begrenzten »Untergattung« innerhalb der frühjüdischen Historiographie, gegenübergestellt. Dabei lautet eine der grundlegenden Fragen des Autors: Wie tragen die Reden bei Josephus zum besseren Verständnis der Areopagrede aber auch zum Verständnis des Verfassers der Apg, sowie des Josephus als antikem Geschichtsschreiber bei? Vítor Hugo Schells Vergleich von formalen und thematischen Merkmalen der Areopagrede mit entsprechenden Merkmalen bei Josephus leistet einen spezifischen Beitrag für die Interpretation dieser Rede und des gesamten lukanischen Werkes.

Vitor Hugo Schell Geboren 1980; 1999-2003 Studium der Ev. Theologie in der Faculdade Luterana de Teologia, Brasilien; 2009-13 Stipendiat der EKD zur Promotion an der Theologischen Fakultät der Friedrich-Schiller-Universität Jena; seit 2013 Dozent für Neues Testament und Biblisches Griechisch in der Lutherischen Theologischen Fakultät - Faculdade Luterana de Teologia, in São Bento do Sul, Brasilien.
Jetzt bestellen:

https://mohrsiebeck.com/buch/die-areopagrede-des-paulus-und-reden-bei-josephus-9783161542275?no_cache=1 order@mohrsiebeck.com

Telefon: +49 (0)7071-923-17

Telefax: +49(0)7071-51104 